\title{
Fault Friction and the Upper Transition from Seismic to Aseismic Faulting
}

Chris Marone and Demian M. Saffer

\section{Abstract}

This paper discusses the processes and mechanical factors that define the seismogenic zone and the updip transition from seismic to aseismic faulting. We review friction laws for granular and clay-rich fault zones and discuss them in the context of the mechanics of stick-slip and the requirements for instability. Seismogenic faulting is driven by the unstable release of stored elastic energy, and thus explanations of the upper stability transition must be couched in terms of fault-zone rheology. We summarize several observations that define the seismogenic zone and its upper boundary, including microseismicity, earthquake afterslip, and the spatial distribution of seismic moment release during large earthquakes. We focus on two hypotheses for the updip limit of seismic faulting. The clay mineral hypothesis posits that a thermally driven transition from a smectite to an illite structure produces a transition from aseismic to seismic behavior. The fault gouge lithification hypothesis posits that the stability transition reflects a threshold consolidation, or lithification, state and a switch from pervasive to localized shear. Existing laboratory data, which cover a limited range of conditions, indicate that the smectite-illite transformation results in an increase in friction but not a transition from stable to unstable behavior. It appears that other depth- and temperature-dependent processes may play an important role in altering the frictional properties of subduction faults and establishing the updip seismic limit.

\section{Introduction}

Plate boundaries can be divided into three main zones as a function of increasing depth: an aseismic updip zone, the seismogenic zone, and a deep aseismic 
zone. Identifying the transitions between these zones and the processes controlling their locations are key goals in understanding the mechanics of slip along subduction zone megathrusts. In this paper, we focus on the updip limit of the seismogenic zone and discuss that stability transition in the context of fault-zone frictional rheology.

Subduction zone megathrusts host a wide range of fault behaviors including interseismic creep, slow earthquakes, earthquakes with normal (fast) rupture velocity, tsunamogenic earthquakes, postseismic slip, and fault healing [Satake, 1994; Draggert et al., 2001, Miller et al., 2002; McGuire and Segall, 2003]. These observations indicate that the limits of the seismogenic zone must be carefully defined in both space and time. For example, the upper limit of unstable faulting as defined by microearthquakes may not necessarily coincide with the updip limit of tsunamogenic faulting or the updip limit of seismic moment release in large earthquakes [e.g., Marone and Scholz, 1988; Davis et al., 1994]. Comparison between the data sets that define the seismogenic zone represents an important opportunity to test hypotheses for the updip stability transition.

Two main hypotheses for the updip stability transition have been proposed. The clay mineral hypothesis posits that a thermally driven transition from a hydrous (smectite) to an anhydrous clay structure (illite) produces a transition from aseismic to seismic behavior. This hypothesis explicitly assumes that smectite exhibits stable, velocity-strengthening frictional behavior and that illite exhibits the necessary conditions for unstable behavior, which (in the context of rate/state friction) means velocity-weakening behavior. The fault gouge lithification hypothesis posits that the stability transition is the result of a change from pervasive shear accommodation within a fault zone, in which grain crushing and consolidation are important, to localized shear within highly consolidated (lithified) fault-zone material. We review and discuss each hypothesis in the context of laboratory friction data and constitutive laws for unstable faulting.

We summarize data from laboratory experiments on the frictional behavior of clays and granular fault gouge. Existing data show that the transformation of a smectite clay structure to an illite structure results in an increase in frictional strength but does not result in a transition from stable frictional behavior to potentially unstable behavior. Existing data support the fault gouge lithification hypothesis as an explanation for the stability transition at the updip limit of the seismogenic zone. However, the available data are limited, and at this time the clay mineral hypothesis cannot be ruled out. In addition, some of the potential consequences of smectite transformation, such as silica cementation and decreased fluid content, may contribute to the transition to consolidated behavior. We suggest that depth- and temperature-dependent processes, such as cementation, consolidation, and slip localization, may play an important role in changing the frictional properties of subduction zone faults and that these processes, in addition to clay mineralogy, should be the focus of future investigation. 


\section{Hypotheses for Stability Transitions That Define the Seismogenic Zone}

While it is generally agreed that the downdip limit of interplate seismicity is controlled by either (1) the onset of crystal plasticity and associated creep behavior at $\sim 350^{\circ}-450^{\circ} \mathrm{C}$, with the exact temperature depending upon mineralogy [e.g., Brace and Kohlstedt, 1980; Sibson, 1982; Scholz, 2002; Hyndman et al., 1997; Peacock and Hyndman, 1999] or (2) the intersection of the subducting slab with the fore-arc mantle wedge in colder subduction zones [e.g., Peacock and Hyndman, 1999]; there is little consensus regarding processes that control the updip limit of seismogenic faulting [e.g., Moore and Saffer, 2001].

It is widely held that the updip onset of seismogenic behavior in subduction zones is tied to the transformation of stably sliding smectite clay to illite. The popularity of this hypothesis is due to (1) studies indicating that the thermally driven dehydration of smectite to illite is completed by temperatures of $120^{\circ}-150^{\circ} \mathrm{C}$ [e.g., Pytte and Reynolds, 1988], (2) laboratory studies that demonstrate a difference in frictional strength between smectite and illite, and (3) correlation between the location of the $150^{\circ} \mathrm{C}$ isotherm along subduction faults predicted by thermal models and the observed seismic front along the Nankai, Cascadia, South Alaska, and Chile subduction zones [Hyndman et al., 1997; Oleskevich et al., 1999].

An alternative hypothesis, offered by Marone and Scholz [1988] to explain the onset of seismicity at depths of 3-5 km on strike-slip faults (and adapted by Davis et al. [1994] for accretionary prisms), is that the updip limit reflects a threshold lithification state within fault gouge. This model recognizes that fault gouge is unconsolidated at shallow depths and that shear is accommodated primarily by distributed deformation within the fault zone. At a critical depth, which depends on fault-slip rate, mineralogy, and geothermal gradient, fault gouge reaches a threshold lithification state and deformation becomes localized. Whereas a poorly consolidated fault gouge exhibits properties of a granular material, highly consolidated and lithified gouge behaves, essentially, as a frictional solid, which may be cut by subfaults. This hypothesis is supported by laboratory observations linking brittle deformation and localized slip with stick-slip behavior and distributed deformation with stable frictional sliding [e.g., Marone et al., 1992; Beeler et al., 1996; Marone, 1998].

As a third hypothesis, Moore and Saffer [2001] argue that the depth of the inferred $150^{\circ} \mathrm{C}$ isotherm corresponds to a wide range of diagenetic processes and increasing effective stress associated with declining fluid overpressure, which, collectively, may explain the transition to unstable slip. This hypothesis shares key features of the critical lithification concept. A fourth hypothesis can be invoked on the basis of the transition from stable to unstable frictional behavior as a function of increased normal stress. Many frictional systems tend to exhibit stable sliding at low normal load and a transition to stick-slip behavior 
above a critical load [Bowden and Tabor, 1950; Rabinowicz, 1956; Dieterich, 1986; Scholz, 1988]. Dieterich [1986] showed how this could be applied to faulting, in terms of loading stiffness and elastic interaction. However, several lines of evidence show that this is not a valid explanation of the upper seismic stability transition, including the depth-frequency distribution of seismicity and its variation with fault-slip rate and the mode of faulting [Sibson, 1982; Marone and Scholz, 1988; Scholz, 2002].

\section{Friction Mechanics and Stability of Faulting}

\section{Fault Strength Versus Stability}

The stability of tectonic faulting is determined by fault-zone rheology and continuum interactions between the fault zone and its surroundings. In the simplest form, seismogenic faulting is driven by the unstable release of stored elastic energy as a fault zone weakens. Thus fault weakening is a necessary condition for instability, and any hypothesis for a stability transition from stable to unstable faulting must include a mechanism for fault-zone weakening. A second requirement for seismic faulting is the existence of stored elastic energy. A fault cannot grow dynamically without an energy source, and this fact leads to a common misunderstanding about the role of frictional strength in earthquake faulting.

It is often assumed that strong faults, with greater elastic energy stored locally, will exhibit unstable slip, whereas weak faults will creep and exhibit aseismic slip. In fact, frictional instability is dictated by (often small) changes in strength rather than the absolute strength. To first order, instability is independent of fault strength (see discussion by Beeler [this volume]). While it is true that earthquake nucleation is unlikely on a fault with nearly zero strength, the converse is not true: strong faults are no more likely to be unstable than weak faults.

\section{Friction Laws for Stick-Slip Versus Stable Sliding}

It has long been recognized that stick-slip frictional instability represents a useful analog for shallow ( $<50 \mathrm{~km}$ ) earthquakes [e.g., Bridgeman, 1936; Bowden and Tabor, 1960], and from these earliest times friction laws were sought to explain unstable sliding. The earliest friction laws lacked predictive power regarding the distinction between stable and unstable sliding, but the introduction of a slip-weakening distance by Rabionowicz [1951, 1956] with later important work by others [e.g., Ida, 1972; Palmer and Rice, 1973] changed that. Rabinowicz's experiments on the nature of static friction and the transition from static to dynamic friction led to a slip-weakening friction law (equation (12.1)) and the 
ability to link (1) weakening on a frictional contact and (2) elastic interaction between the contact and its continuum surroundings.

$$
\begin{array}{ll}
\mu=\mu_{s}-\left(\mu_{s}-\mu_{d}\right) u / L & u \leq L \\
\mu=\mu_{d} & u>L
\end{array}
$$

Here, $\mu_{s}$ is the coefficient of static friction, $\mu_{d}$ is the coefficient of dynamic friction, $u$ is slip, and $L$ is the slip-weakening distance.

Modern friction constitutive laws have moved beyond slip weakening to consider time- and slip-dependent restrengthening and variations in friction with slip rate. These laws can reproduce, in a simplified manner, the entire seismic cycle including earthquake nucleation, dynamic rupture, postseismic slip, and interseismic healing. As a result, testable hypotheses for the seismic cycle and earthquake data can be couched in terms of constitutive laws.

Spring-Slider Analog and a Critical Stiffness for Instability The essential elements of an earthquake-like frictional instability can be understood with reference to an elastic element coupled to a massless block that obeys a slipweakening friction law at its sliding contact (fig. 12.1). We may assume unit

Figure 12.1 Spring-block model and continuum interactions for stick-slip friction. $K$ is the spring constant and $\mu_{s}$ is the coefficient of static friction. Note that frictional resistance $f$ decreases suddenly when the block begins to move at $x^{\prime}=0$. Energy is conserved, such that the block continues to slide for some distance beyond the point where $f$ is greater than $K$.
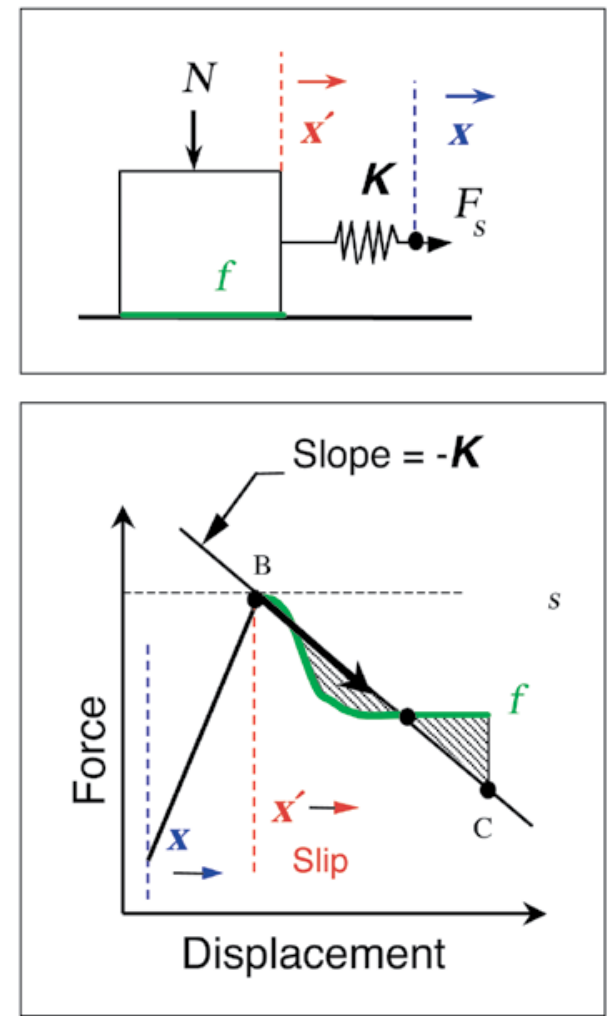
contact area at the base of the slider, so that forces and stresses can be used interchangeably in the discussion that follows. By assumption of a static coefficient of friction, the fault is locked until the remotely applied force $\mathrm{F}_{s}$ exceeds the friction force (point B in fig. 12.1). At this point, slip may occur by stable sliding, for which the spring force is balanced by the friction force, or by stickslip. The stability of each slip increment is dictated by the relative magnitude of the change in spring force relative to the change in frictional force. For a slip-weakening friction law (fig. 12.2), the friction force decreases with slip at a rate given by $N\left(\mu_{s}-\mu_{d}\right) / L$, where $N$ is normal force. Regardless of the friction

(a)

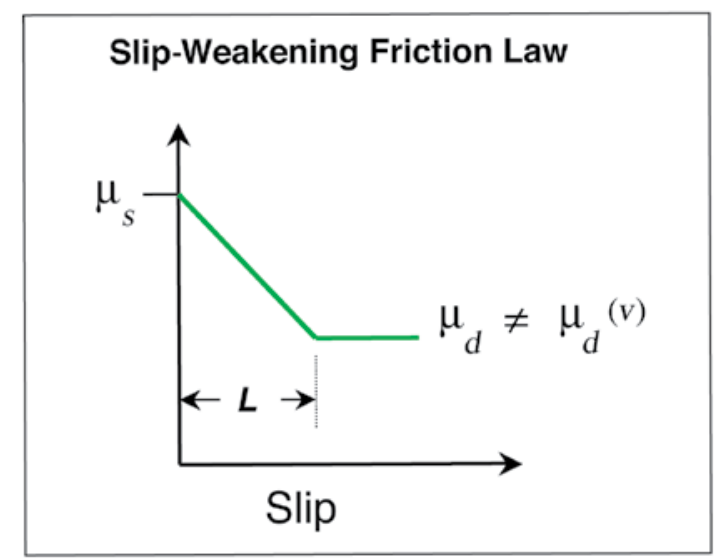

(b)

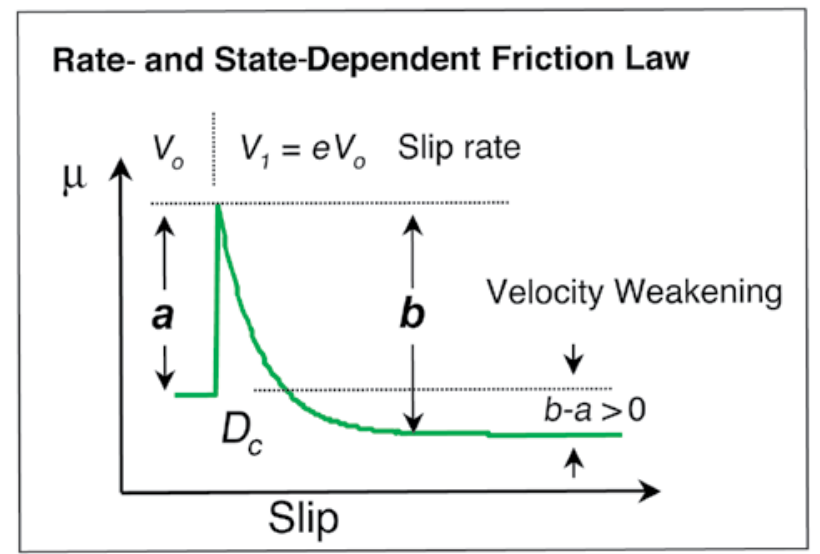

Figure 12.2 Displacement dependence of friction for slip weakening and rate-state friction laws. (a) $L$ is the slip-weakening distance. Note that dynamic friction is independent of slip velocity. (b) Friction response to a sudden perturbation in slip velocity. The friction rate parameter $(a-b)$ describes the dependence of steadystate sliding friction on slip velocity. 
behavior, the spring force reduces with slip at a rate given by the spring constant $K$ (fig. 12.1). If the magnitude of the reduction in frictional force exceeds the change in spring force, a force imbalance occurs and stick-slip behavior results.

It is convenient to define the rate of frictional weakening as a critical stiffness $K_{c}$ :

$$
K_{c}=N\left(\mu_{s}-\mu_{d}\right) / L
$$

With the limitations imposed by the simplified friction law and by neglecting mass of the slider block, the spring-block system undergoes stick-slip if $K<K_{c}$ and stable sliding otherwise.

The spring-slider system of figure 12.1 is clearly woefully simplistic compared to seismogenic plate boundaries. Fault-zone frictional properties are more complex than can be described by a slip-weakening friction law, and elastic interactions between a fault patch that enlarges with slip and its surroundings are not well characterized by a one-dimensional spring constant. Nevertheless, the essential elements that determine the stability of the spring-slider system (e.g., equation (12.2)) form the basis for all other, more complex analyses. For descriptions of recent works on slip stability, including treatments and discussion of the role of inertia and pore fluids, readers are directed to the works and summaries of Rice [1983], Rice and Ruina [1983], Rice [1993], Roy and Marone [1996], Segall and Rice [1995], Perfettini et al. [2001], and Scholz [2002].

Rate-State Friction A major limitation of the slip-weakening friction model is that only a single earthquake can be studied. Slip weakening provides no basis for repetitive stick-slip failure, interseismic fault restrengthening or for modeling tsunamogenic earthquakes or creep events. While the updip limit of seismic faulting could be described by slip weakening (the transition from seismic to aseismic faulting would be ascribed to a change from slip weakening to slip strengthening, in which the dynamic friction exceeded the static value), testable, processes-based hypotheses for the limits of the seismogenic zone are beyond the scope of this class of friction laws.

Rate- and state-dependent friction laws (fig. 12.2) were developed to describe the dependence of steady-state sliding friction on slip rate and the variations of friction with contact time and slip [Dieterich, 1979; Ruina, 1983]. In the context of rate and state constitutive laws, there is no distinction between static and dynamic friction; both are simply special cases of a more generalized view of the variation of friction with slip rate and contact state. The state variable describes physicochemical changes of the frictional contacts (or the fault zone) as a function of contact time, slip history, normal stress, and chemical environment, in addition to other factors [e.g., Marone, 1998; Scholz, 2002].

Figure 12.2 shows the essential elements of rate and state friction behavior. The coefficient of friction is a function of slip rate $V$ and a state variable. 
Variations in friction are described by dimensionless constants $a$ and $b$ and critical slip distance $D c$. The parameter $a$ describes the instantaneous change in frictional strength for a sudden perturbation in slip rate, and $b$ describes subsequent time- and slip-dependent evolution (fig. 12.2). The steady-state coefficient of sliding friction varies with the log of slip velocity $V$ as

$$
\Delta \mu_{S S}=(a-b) \Delta \ln V
$$

If parameter $a$ exceeds parameter $b$, steady-state friction increases with sliding velocity and friction is said to exhibit velocity strengthening. This is a type of viscous behavior, as can be seen by replacing velocity with strain rate and noting that shear strength increases with increasing strain rate. Velocityweakening friction occurs when the evolution parameter $b$ is larger than parameter $a$. As shown in figure 12.2, velocity weakening implies that the steadystate frictional strength decreases as sliding velocity increases.

For a massless spring-block system (e.g., fig. 12.1) that obeys rate and state friction, the stability of sliding is governed by a critical stiffness $K_{c}$ given by

$$
K_{c}=\sigma_{n}(b-a) / D_{c}
$$

where $\sigma_{n}$ is normal stress and we assume unit area for the slider block for comparison to equation (12.2). Unstable, earthquake-like, sliding of a spring-block system occurs if $K<K_{c}$ and stable sliding occurs otherwise. A discussion of stability analyses and additional background can be found in the work of Rice and Ruina [1983].

Equation (12.4) conveys two essential points. First, instability requires velocity weakening; sliding is always stable if parameter $a$ is larger than $b$, because $K$ is $>K_{c}$. Second, the sufficient condition for unstable motion involves only the velocity dependence of friction, the critical slip distance, normal stress, and the stiffness of the surroundings $K$. The degree of potential instability increases for larger values of $K_{c}$. As is evident from equations (12.2) and (12.4), in the context of slip-weakening friction laws the distinction between stable and unstable sliding does not depend on the absolute frictional strength.

Frictional Properties of Rock and Granular Fault Gouge Laboratory experiments indicate that the frictional properties of fault rocks range from strongly velocity strengthening to strongly velocity weakening. Their behavior depends on numerous conditions, including temperature, the presence and thickness of a gouge layer, rock or gouge composition, grain size (for gouge), normal stress, humidity, and shear strain. For quartzo-feldspathic rocks, temperatures higher than $\sim 350^{\circ} \mathrm{C}$ generally result in velocity-strengthening behavior [e.g., Blanpied et al., 1998]. At lower temperatures, many factors have subtle but important effects on the velocity dependence of steady-state friction, and it is difficult to predict the frictional behavior of materials a priori [e.g., Tullis, 
1988]. Some clays and serpentinite minerals tend to exhibit velocity strengthening [e.g., Reinen et al., 1994]. In general, smoother frictional surfaces tend to exhibit velocity weakening, whereas rougher surfaces and conditions that favor high rates of wear tend to exhibit velocity strengthening [Dieterich, 1981; Marone et al., 1990]. Also, rock-on-rock sliding under stresses and temperatures appropriate for the upper crust tends to result in velocity-weakening frictional behavior [Marone, 1998].

In experiments on crushed rock and granular fault gouge, velocity strengthening is associated with pervasive strain and conditions that promote comminution, whereas shear localization tends to reduce the parameter $(a-b)$ and result in velocity weakening [e.g., Beeler et al., 1996; Mair and Marone, 1999]. Laboratory experiments show that compaction and dilation play a key role in determining the frictional behavior of fault gouge. Under nominally dry conditions the rate of dilatancy with shear strain varies systematically with sliding velocity (or strain rate) and influences the frictional strength and its velocity dependence [Marone et al., 1990].

In the presence of fluids, pore-volume changes may have significant effects on fault strength and the seismic cycle [e.g., Sleep and Blanpied, 1992, 1994; Segall and Rice, 1995]. The degree of shear localization and the shear band width have been shown to influence the critical slip distance; such that $D_{c}$ decreases as the degree of shear localization increases [Marone and Kilgore, 1993]. Because a reduction in $D_{c}$ tends to promote instability (equation (12.4)), shear localization plays a key role in fault stability [Marone, 1998].

Nucleation of Instability and Minimum Earthquake Size A velocity-weakening fault zone may exhibit seismic slip if the local elastic stiffness $K$ is less than $K_{c}$. The one-dimensional stiffness $K$ of a region around a fault patch is proportional to the shear modulus $G$ divided by the patch radius. This means that for a given set of friction parameters, slipping patches larger than a critical size $\left(R_{\text {crit }}\right)$ will be unstable, where $R_{\text {crit }}=C G D_{c} / \sigma_{n}(b-a)$ and $C$ is a proportionality constant. Thus the critical patch radius for instability can be related to $K_{c}$ [Dieterich, 1986], and this dimension corresponds to a minimum earthquake size [Richardson and Jordan, 2002]. Note that a theoretical earthquake source of dimension $R_{\text {crit }}$ will radiate zero seismic energy, and thus, to be detected seismically, an unstable fault patch would need to exceed $R_{\text {crit }}$. Theoretical and laboratory-based estimates of the minimum earthquake size range from magnitude -2 to 0 or slightly larger. While this value is highly uncertain for any given fault zone, it is likely to be much smaller than the earthquake detection threshold for most seismic arrays. Thus, when considering historical catalogs or large, high-resolution seismic data sets, it is reasonable to assume that recordable earthquakes will nucleate in any region that exhibits velocity-weakening frictional behavior, no matter how small the value of $(a-b)$. 


\section{Stability Transitions and the Seismogenic Zone}

In the context of rate and state friction, a fault zone that exhibits velocitystrengthening frictional behavior will undergo aseismic deformation. This implies that the seismogenic zone as defined by earthquake nucleation maps the transition from stable, velocity-strengthening frictional behavior to unstable, velocity-weakening behavior (fig. 12.3).

Figure 12.3 shows a depth-frequency distribution of seismicity for an active, mature fault zone, in which the upper region is dominantly aseismic. The updip and downdip limits of the seismogenic zone are taken as the depths below which (and above which, respectively) 90\% of the seismicity occurs. Marone and Scholz [1988] studied continental faults and showed that the upperstability transition occurs only for mature fault zones. Young faults and those with long recurrence intervals or negligible gouge zones do not exhibit an upper stability transition [Marone and Scholz, 1988]. They argued that the updip limit of the seismogenic zone marks a transition from dominantly pervasive shear of poorly consolidated fault gouge to localized slip within indurated gouge. In this model, the transition depth reflects a balance between granulation, driven by fault slip, and lithification driven by pressure, fluids, and elevated temperature. This is the laboratory basis for the critical lithification hypothesis discussed above.

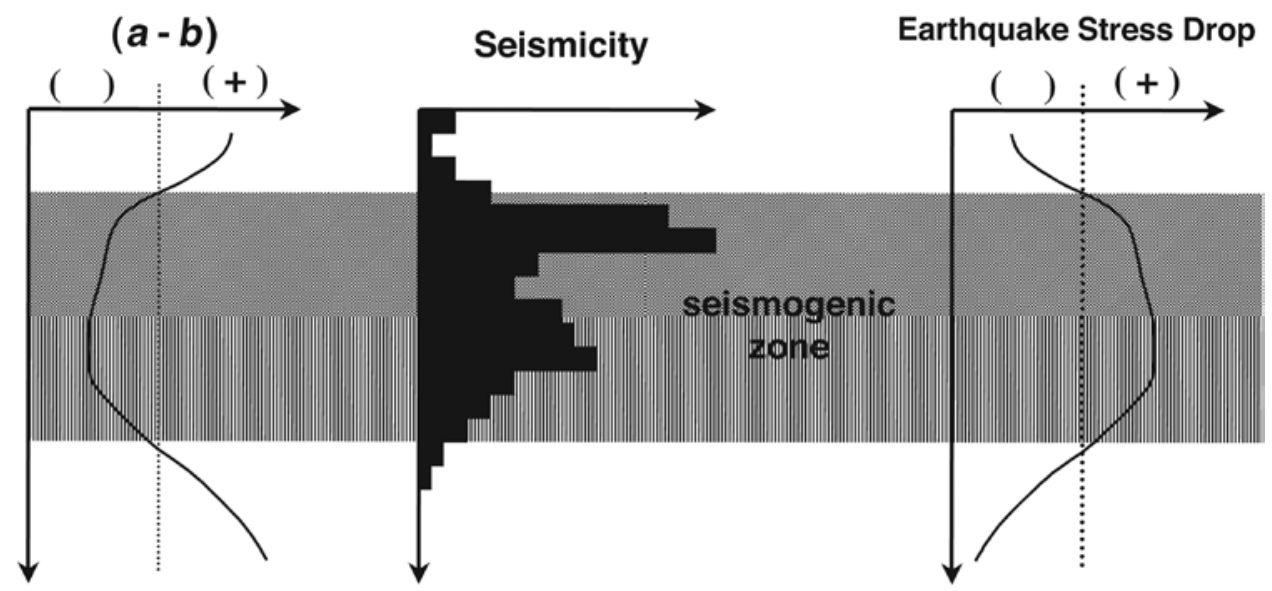

Figure 12.3 Definition of the seismogenic zone. Center panel shows a depth-frequency distribution of seismicity. The updip and downdip limits of the seismogenic zone are taken as the depths below which (and above which, respectively) $90 \%$ of the seismicity occurs. Left and right panels show schematic relationship between seismogenic zone and the parameters that dictate earthquake nucleation $(a-b)$ and seismic moment release for a propagating rupture (stress drop). Note that dynamic stress drop is proportional to slip speed, $(a-b)$, and normal stress; hence details of the shape are schematic only. 
At a given depth, earthquake nucleation is dictated by the local frictionrate parameter $(a-b)$, normal stress, and the critical stiffness $K_{c}$. However, large earthquakes may propagate beyond the limits of the seismogenic zone defined by nucleation (fig. 12.4). Ruptures that are sufficiently energetic may extend outside the region of velocity weakening, and in some cases, such events may rupture completely through the upper stable region. Dynamic rupture of a velocity-strengthening material implies negative stress drop (fig. 12.3) because the local, dynamic fault strength exceeds the initial stress level. Events with significant regions of negative stress drop generally have distinctive characteristics, such as low-average rupture velocity.

The updip limit of seismicity on mature continental faults is generally at a depth of 3-5 km, and this depth is in rough agreement with the upperstability transition along the southwest segment of the Nankai Trough, which is generally taken to be $4-5 \mathrm{~km}$ below the seafloor (fig. 12.4). Modeling of the 1946 Nankai earthquake and the associated tsunamogenic faulting indicates a strong reduction in coseismic slip above $5 \mathrm{~km}$ (fig. 12.5). Coseismic rupture along the more vertical, splay fault (within the potentially overconsolidated accretionary wedge sediments) is consistent with strong velocity strengthening along the main décollement (fig. 12.5).

Earthquake Afterslip The 1979 Imperial Valley, California, earthquake ruptured a section of the seismogenic fault overlain by a thick layer of unconsolidated sediment [Fuis et al., 1982]. Both kinematic modeling of the seismic strong motion records [Archuleta, 1984] and dynamic modeling of the coseismic rupture [Quin, 1990] indicate that the region above $5 \mathrm{~km}$ exhibits strong velocity-strengthening characteristics (fig. 12.6). Negative stress drop implies that the dynamic fault strength exceeds the initial stress level; hence coseismic rupture into the upper region results in a sudden increase in stress there. As a consequence, the fault slips there during the period immediately following the

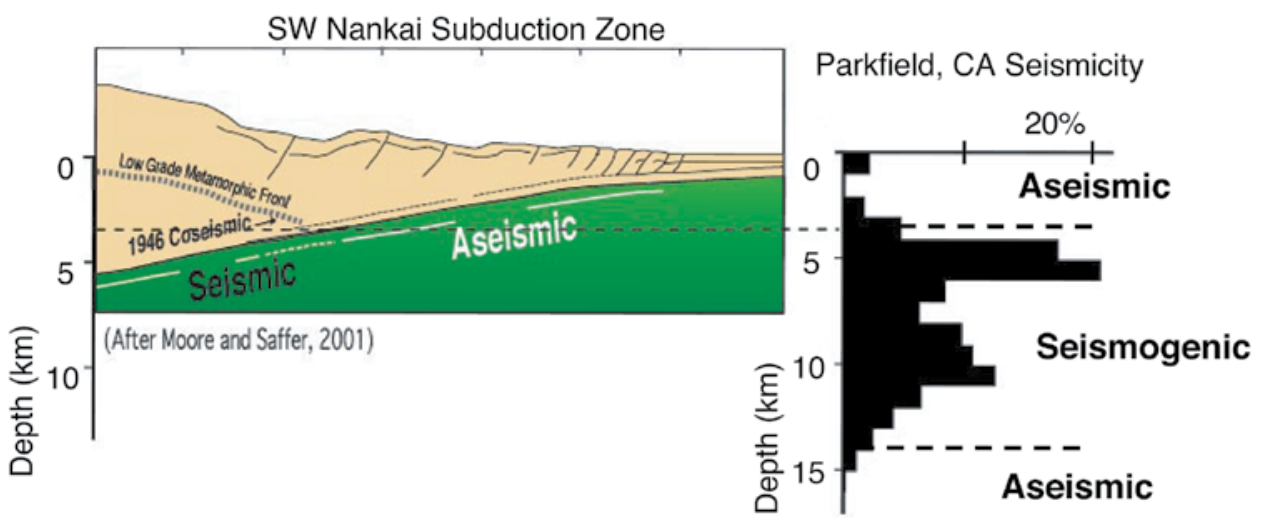

Figure 12.4 Data sets that define the seismogenic zone and the upper transition from unstable to stable frictional behavior for a subduction zone megathrusts (Nankai) and a continental strike-slip fault (Parkfield). 


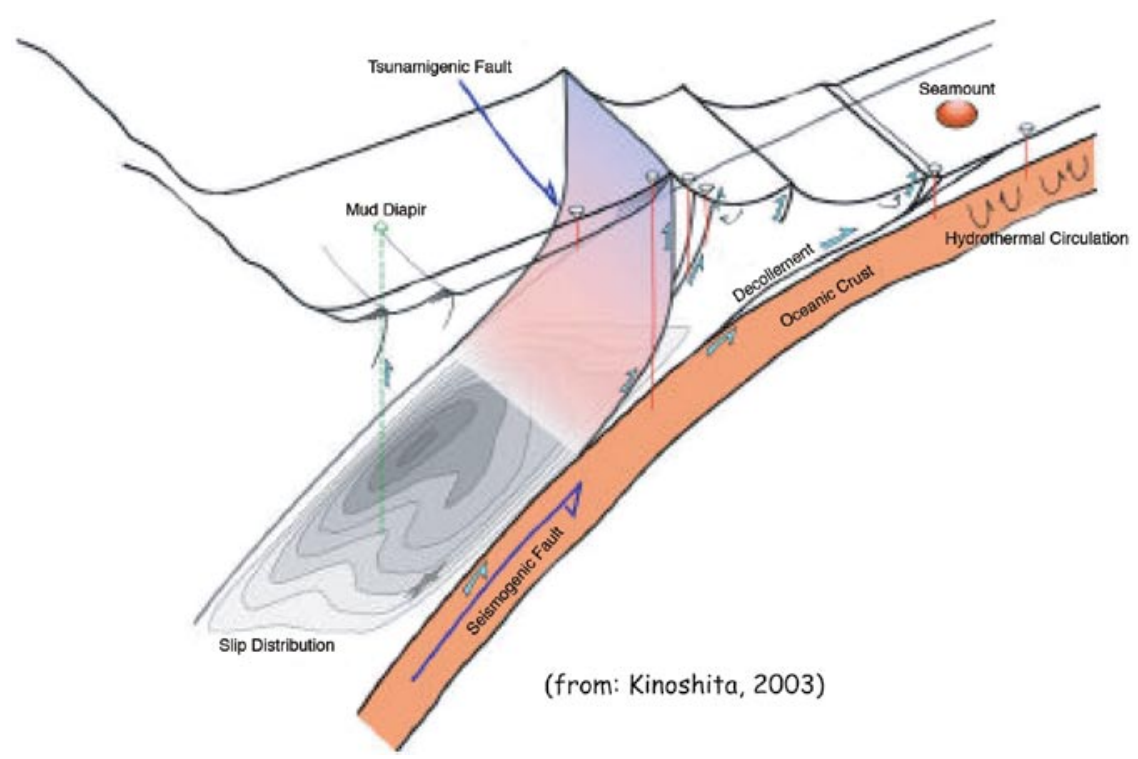

Figure 12.5 Geometry and major faults of the Nankai accretionary prism and subduction zone. Contours show slip distribution for the 1944 and 1946 Nakaido earthquakes as inferred from tsunami data and strong-motion seismic records. Courtesy of M. Kinoshita (personal communication, 2003).
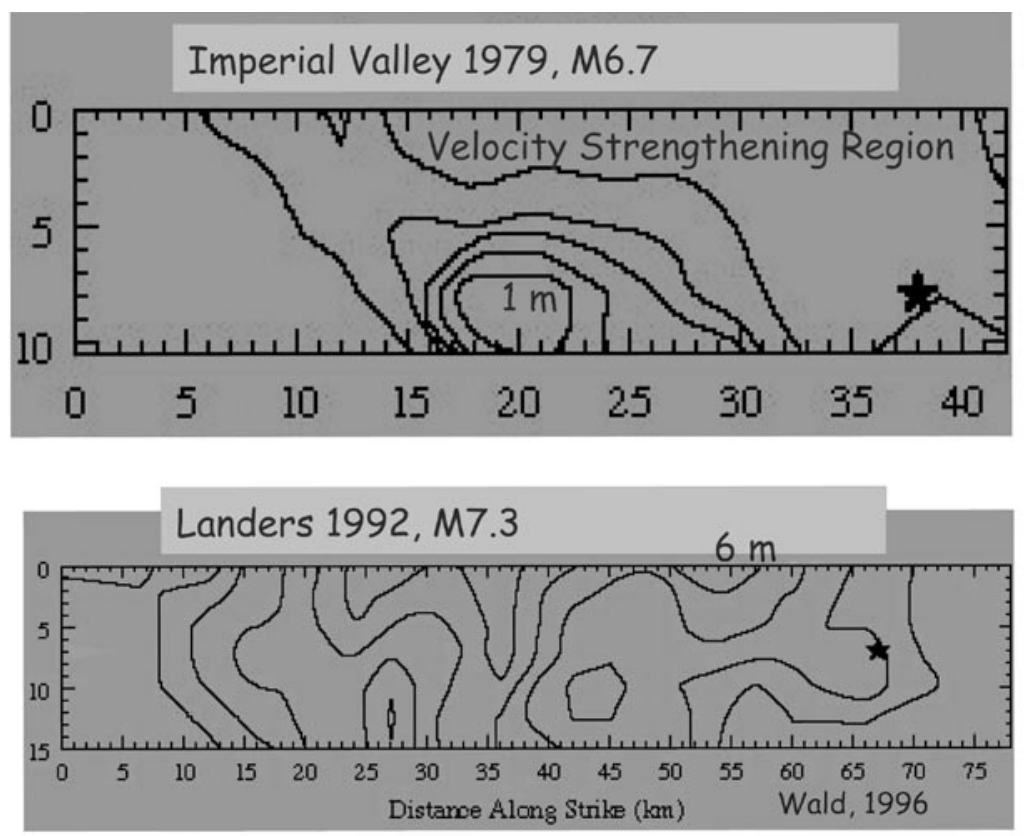

Figure 12.6 Along-strike sections of the 1979 Imperial Valley, California, earthquake and the 1992 Landers earthquake showing contours of coseismic slip. The Imperial fault contains a thick zone of unconsolidated sediments in the upper $3-4 \mathrm{~km}$. The coseismic slip contours are consistent with velocity strengthening frictional behavior in this region. (Data from Wald and Heaton [1994]). 
earthquake, which is known as earthquake afterslip. Marone et al. [1991] discussed a model for earthquake afterslip and found good agreement between the depth of the velocity-strengthening region inferred from rate-state friction laws, using laboratory-derived values of $(a-b)$, and independent estimates of the upper-stability transition based on microseismicity [Doser and Kanamori, 1986] and crustal structure [Fuis et al., 1982].

A prediction of the afterslip model is that ruptures on immature faults will not exhibit buried coseismic slip or shallow afterslip because the velocityweakening zone extends to the surface, and no region of negative coseismic stress drop occurs. The 1992 M 7.3 Landers earthquake and the 1999 M 7.1 Hector Mine earthquake show exactly this behavior (fig. 12.6). Strong rupture extended to the surface and the coseismic slip contours indicate no updip reduction of slip.

\section{Review of Relevant Laboratory Friction Data}

Laboratory studies have investigated many factors that influence the frictional properties of fault-zone rocks. These factors include initial sediment composition and grain size distribution [e.g., Lupini et al., 1981; Logan and Rauenzahn, 1987; Bos and Spiers, 2000, 2002], normal stress and slip velocity [Marone et al., 1990; Beeler et al., 1996; Mair and Marone, 1999], variations in mineralogy as might be expected with increasing fault plane depth [e.g., Saffer and Marone, 2003], increasing consolidation [Zhang et al., 1993], and cementation.

At subduction zones, megathrusts initiate within sediment of the incoming plate, or are at least bounded by the sediment on one side; the fault gouge is typically derived from these sediments [e.g., Tobin et al., 2001]. The sediment and fault zones dominantly contain a mixture of quartz, clay minerals (typically illite, smectite, chlorite, and kaolinite), and plagioclase. For example, sediments incoming to the southwest Nankai subduction zone, recovered by drilling on Ocean Drilling Program (ODP) Leg 190, sampled the décollement (or its stratigraphic equivalent outboard of the trench), contain $\sim 37-58 \%$ clay minerals, $30-42 \%$ quartz, $7-13 \%$ plagioclase, and $0-11 \%$ calcite [Moore et al., 2001]. Of the clay minerals, $74-83 \%$ is illite-smectite; the remainder is dominantly chlorite. With progressive burial and heating, the smectite in these sediments transforms to illite. The clay fraction of some fault gouges is enriched in illite when compared to the mineralogy of wall rocks [Vrolik, 1990; Vrolik and Van der Pluijm, 1999]. However, the clay mineralogy of subduction zone faults, at least as observed at shallow depths, does not follow this pattern [e.g., Underwood et al., 1993; Moore et al., 2001; Deng and Underwood, 2001].

We summarize recent results on granular quartz, smectite and illite clay, and clay-quartz mixtures, focusing on works of Saffer et al. [2001], Saffer and Marone [2003], and Mair and Marone [1999]. The illite shale material discussed here is comparable in composition to some clay-rich fault gouges used in previous experimental work on illite gouges and also to the marine sediments 
that serve as source material for fault gouge in subduction zones [e.g., Saffer and Marone, 2003]. These studies employed the double-direct shear configuration. Layers were sheared under constant normal stress, ranging from 5 to $150 \mathrm{MPa}$, sliding velocities of $0.1 \mu \mathrm{m} / \mathrm{s}$ to a few millimeters per second, and a nominally dry condition or controlled humidity at room temperature. In all tests, normal stress across the layers was maintained by a fast, hydraulically driven servocontroller, and changes in porosity were monitored continuously as a function of slip and time. Materials consisted of Ca-Smectite clay (obtained as a powder from GSA Resources), illite-shale (obtained from Wards Geological Supply), and quartz powder (F-110, obtained from the US silica company). F-110 is a pure quartz sand $\left(99.8 \% \mathrm{SiO}_{2}\right)$ with minor amounts of $\mathrm{Fe}_{2} \mathrm{O}_{3}, \mathrm{Al}_{2} \mathrm{O}_{3}$ $(<0.1 \%$ each), and other oxides. Particles are rounded to subangular and the size distribution is as follows: 8\% 53-75 $\mu \mathrm{m}, 25 \% 75-106 \mu \mathrm{m}, 44 \% 106-150$ $\mu \mathrm{m}, 18 \%$ 150-212 $\mu \mathrm{m}, 4 \% 150-212 \mu \mathrm{m}$, with $<1 \%$ beyond the upper and lower limits. Clay particles ranged from 2 to $500 \mu \mathrm{m}$. Details of the XRD analyses can be found in the work of Saffer and Marone [2003].

\section{Frictional Strength of Illite Shale, Smectite, and Quartz-Smectite Mixtures}

Figure 12.7 shows basic stress-strain characteristics for four materials. Quartz and illite shale are frictionally strong and exhibit coefficients of sliding friction of 0.62 and 0.55 , respectively. Smectite friction is low, $\sim 0.25$ at a normal stress of $20 \mathrm{MPa}$, and the 50/50 clay-quartz mixture has an intermediate strength, with a friction coefficient of $\sim 0.4$. Pure smectite shows a distinct peak stress with subsequent weakening over the shear strain range from 50 to $200 \%$ (fig. 12.7a). The other materials obtain a steady-state, residual friction value after shear strains of 3 to 4 . The experiments shown in figure 12.7 include sections of constant loading velocity as well as numerous perturbations in the loading rate, discussed below, and these appear as transients and second-order variations in the normalized shear strength.

Frictional strength varies systematically with quartz content in smectitequartz mixtures (fig. 12.7b). The mixture strengths are somewhat lower than predicted by simply averaging the strength of the end members; e.g., compare the $50 / 50$ mixture with the $90 / 10$ and 10/90 mixtures in figure $12.7 \mathrm{~b}$ (see discussion of polyphase mixtures in the work of Beeler [this volume]). During initial loading at $25 \mathrm{MPa}$ normal stress, layers with greater clay content exhibit a more distinct peak stress (fig. 12.7b). In these experiments the shear load was removed and reapplied at a shear strain of $\sim 2$. The reloading curves do not show a peak stress. This is consistent with the interpretation that the peak and subsequent weakening result from rotation and alignment of clay grains [e.g., Lupini et al., 1981; Saffer and Marone, 2003]. Clay grains have random orientation when the layers are initially prepared. The application of normal load compacts the gouge layer, but clay grain alignment occurs primarily during shear and is not a reversible process. 
(a)

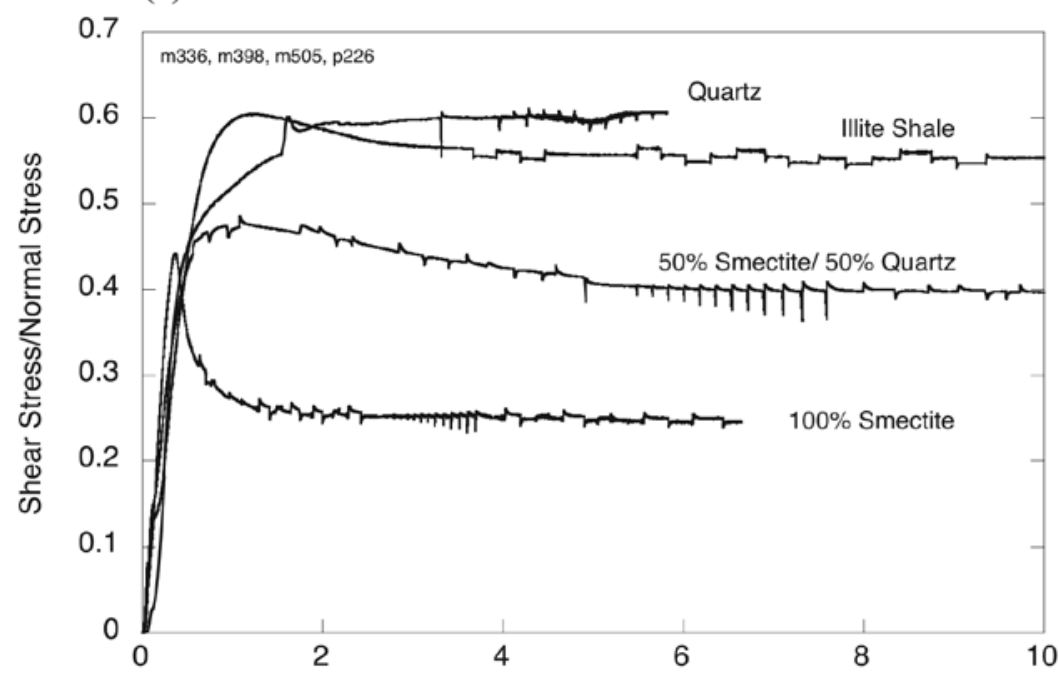

(b)

Shear Strain

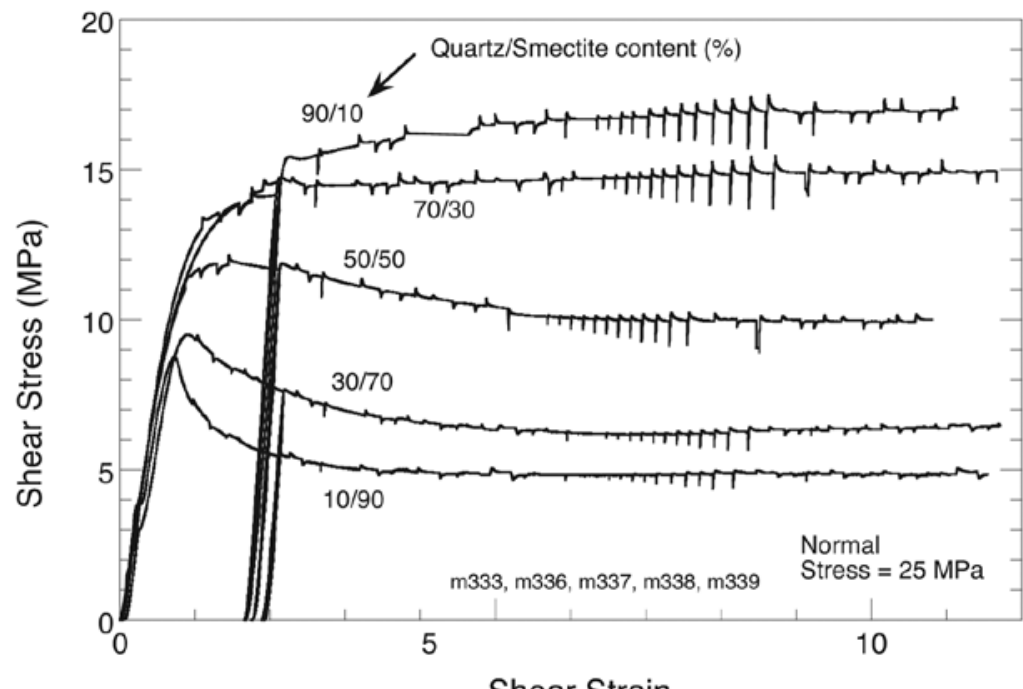

Figure 12.7 Laboratory friction data. (a) Friction (shear stress/normal stress) versus shear strain for four materials. (b) Stress-strain behavior as a function of quartz content in layers of smectite clay. [After Saffer and Marone, 2003]

The four materials exhibit a range of failure behaviors as a function of increasing normal stress from 5 to $150 \mathrm{MPa}$ (fig. 12.8). As is typical for gouge, all have cohesion values near zero. For pure smectite gouge the coefficient of sliding friction ranges from 0.07 to 0.30 , and decreases with increasing normal stress (fig. 12.8). Smectite gouge undergoes a transition from brittle to pressure insensitive deformation at a normal stress of $35 \mathrm{MPa}$; this value also marks a change in the angle of internal friction for the 50/50 smectite-quartz mixture. 
(a)

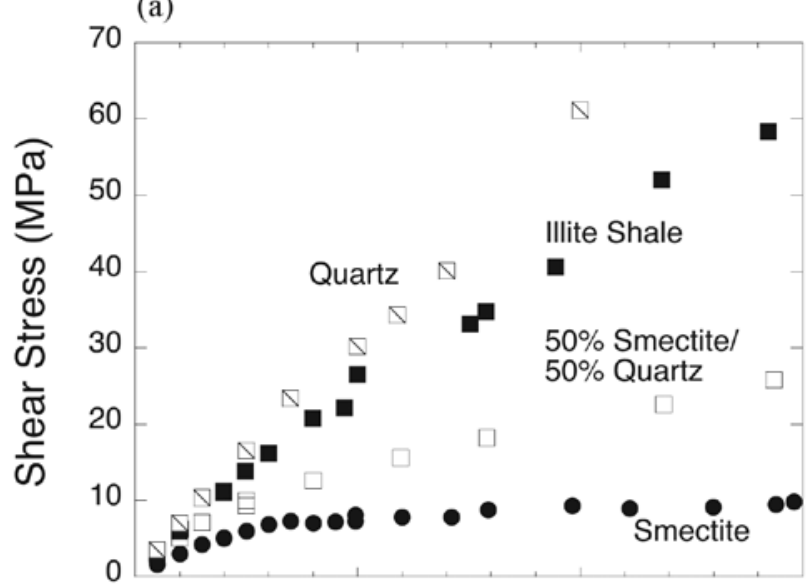

(b)

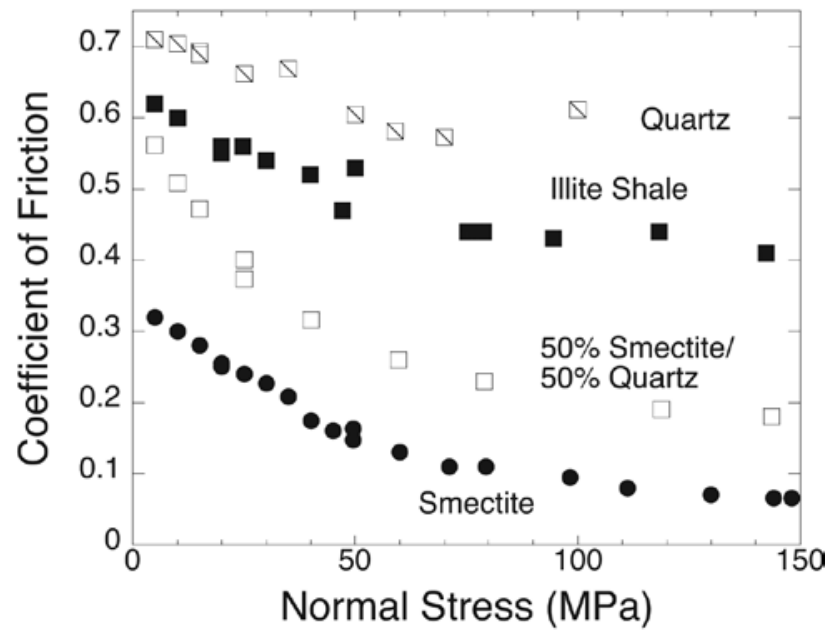

Figure 12.8 Failure envelopes and coefficient of sliding friction for four materials. Note that smectite shows nonpressure sensitive strength above normal stresses of 30-40 MPa. [After Saffer and Marone 2003]

For illite shale the coefficient of sliding friction ranges from $0.41-0.63$ over the range of normal stresses. These values are consistent with previous work on clays and clay shales [Logan and Rauenzahn, 1987; Morrow et al., 1982; Morrow et al., 1992; Morrow et al., 2000]. Illite shale has nearly the same failure envelope as quartz and each exhibits a constant angle of internal friction over this range of normal stresses (fig. 12.8).

\section{Frictional Behavior of Illite Shale, Smectite, and Quartz-Smectite Mixtures}

Velocity stepping experiments are done to assess the transient and steady-state frictional response (fig. 12.9). Figure $12.9 \mathrm{~b}$ gives the full rate and state friction 
law and the relation to describe elastic coupling between the testing apparatus and shearing layers. Figure 12.9a shows results for velocity stepping tests on layers of illite-shale and indicates velocity-strengthening frictional behavior (i.e., the steady-state coefficient of sliding friction increases with increasing sliding velocity). Equations (12.1), (12.2), and (12.5) (fig. 12.9b) are solved to model the full transient and steady-state frictional response; these models provide good fits to the range of materials discussed here [Mair and Marone, 1999; Saffer and Marone, 2003].

As shown by Saffer et al. [2001], Ca-smectite exhibits velocity-weakening behavior under a limited set of conditions of low normal stress and sliding velocities. Here we focus only on the sliding velocities $<20 \mu \mathrm{m} / \mathrm{s}$ (fig. 12.10). Smectite exhibits a clear transition from velocity-weakening at normal stresses
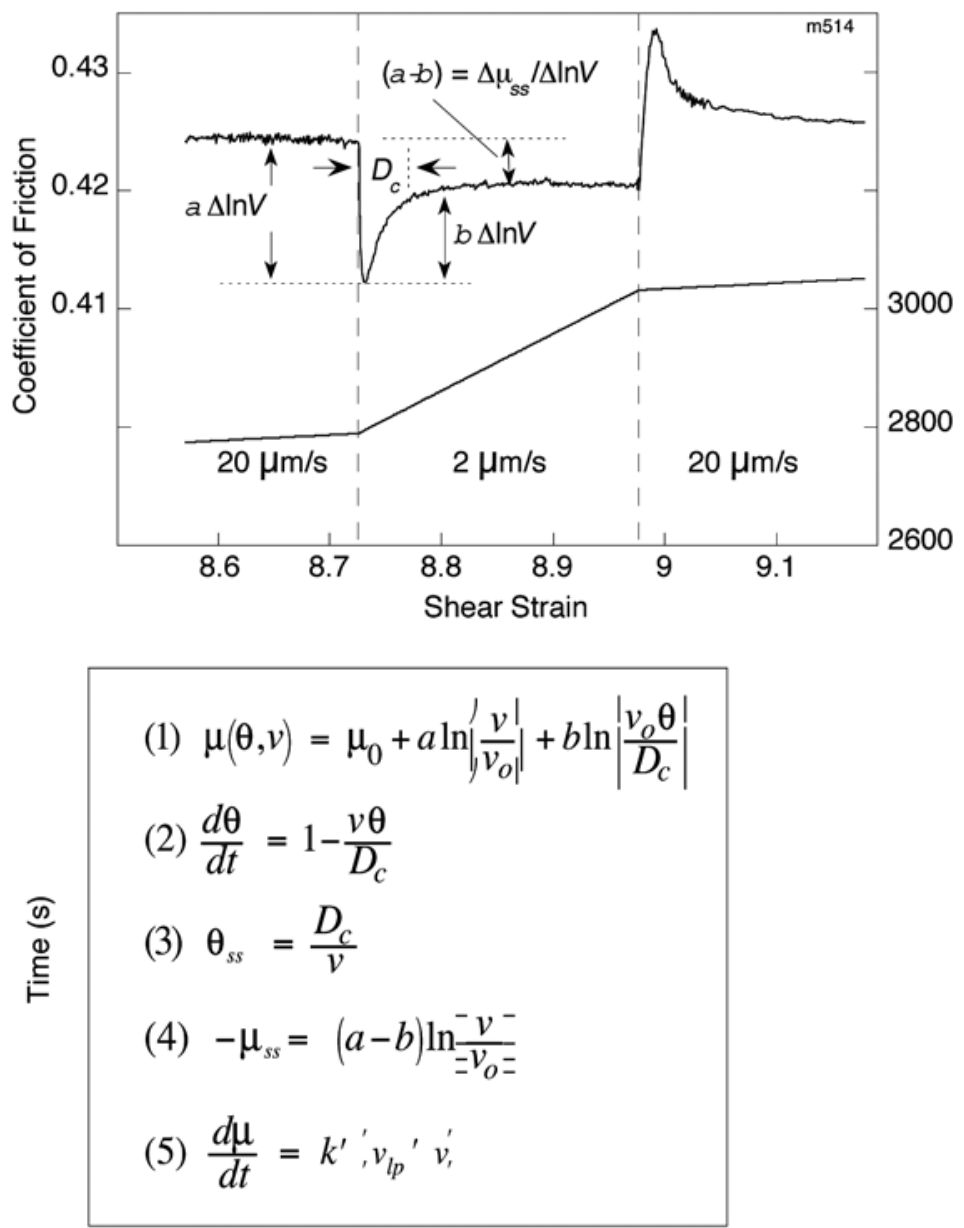

Figure 12.9 (a) Rate state friction behavior, showing velocity-strengthening behavior.

(b) Friction constitutive equations and relation for elastic interaction with the testing machine. 
below 35-40 MPa to velocity strengthening for higher normal stresses. The minimum value of $(a-b)$ is $=-0.0025$ at a normal stress of $5 \mathrm{MPa}$. Maximum values of $(a-b)$ of 0.0015 to 0.002 are observed at normal stresses $>75 \mathrm{MPa}$ and are consistent with the value of 0.005 reported by Morrow et al. [1992] for similar normal stresses and sliding velocities and under saturated conditions (however, note that those experiments do not reach a steady-state friction condition and thus the validity of the results on velocity dependence are unclear). For a given normal stress and sliding velocity, $(a-b)$ does not vary over a range of shear strain from 3 to 14 [Saffer and Marone, 2003].

In contrast, illite shale exhibits only velocity-strengthening behavior over a wide range of normal stresses (5-150 MPa) and sliding velocities (0.1-200 $\mu \mathrm{m} / \mathrm{s}$ ) (fig. 12.10). Values of $(a-b)$ range from $\sim 0.0015$ to 0.0035 , and unlike smectite, do not vary appreciably with normal stress (fig. 12.8a) or velocity. For illite gouge, values of $(a-b)$ are also generally independent of shear strain at normal stresses of 10-50 MPa [Saffer and Marone, 2003]. The values of $(a-b)$ (0.0015-0.004) reviewed here are consistent with a value of $(a-b)=0.005$ reported by Morrow et al. [1992] for illite shale under normal stresses of 100 and $300 \mathrm{MPa}$ (however, note that those experiments do not reach a steady-state friction condition, and thus the validity of the results on velocity dependence are unclear).

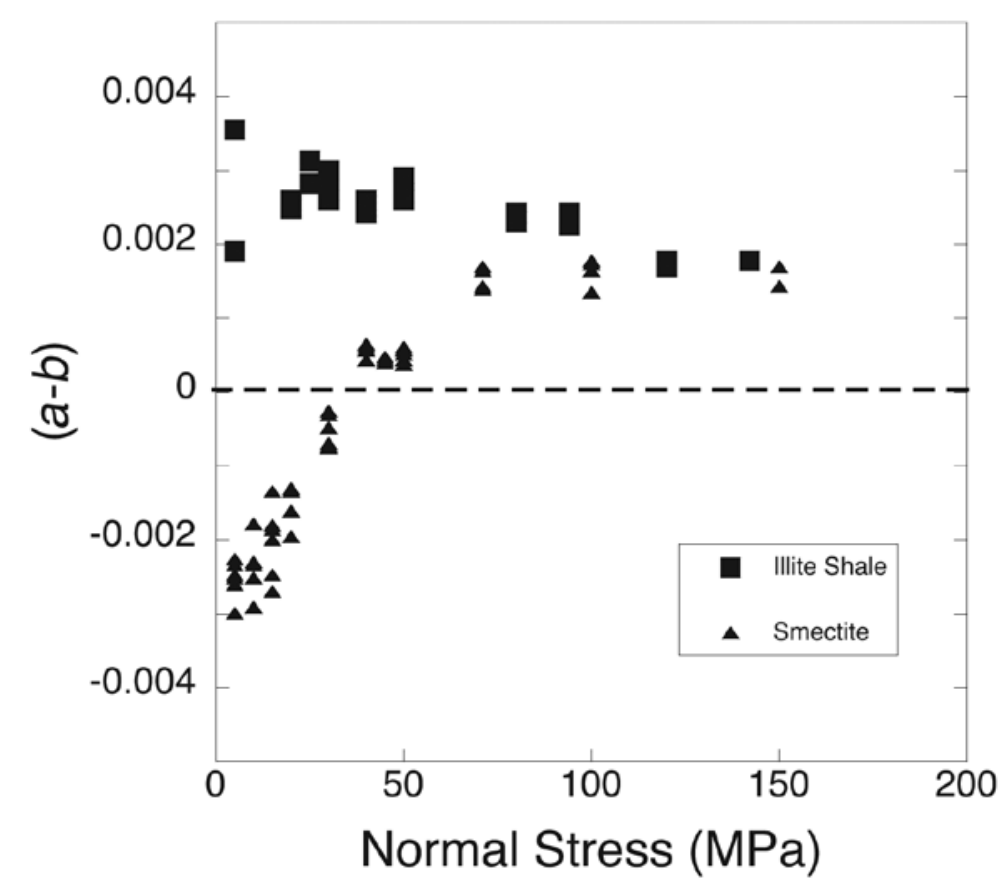

Figure 12.10 Friction-rate parameter for illite-shale and smectite clay. Smectite shows a transition from velocity-weakening frictional behavior at low normal stress to velocity-strengthening behavior at higher normal stresses. Data from Saffer and Marone [2003] 
The Dieterich rate and state friction law provides good fits to the clay gouge data [Saffer and Marone, 2003]. Visual comparisons of data and model are very close, allowing for some misfit associated with data noise. For illite shale gouge the friction parameter $a$ exceeds the evolution parameter $b$ throughout the range of velocities and normal stresses studied, consistent with the results showing steady-state velocity strengthening (figs. 12.9 and 12.10). Both friction parameters for illite show a minimum at normal stresses of 10-20 MPa and maximum values at $5 \mathrm{MPa}$ [Saffer and Marone, 2003]. The critical slip distance $D_{c}$ is $10-30$ $\mu \mathrm{m}$ for 3-4 mm thick layers of illite shale, independent of normal stress.

In order to quantify volume changes in gouge layers associated with velocity stepping, layer thickness changes are recorded continuously during shear. The tendency of a gouge layer to dilate or contract with changes in sliding velocity is important for understanding velocity or strain rate dependence of strength and fabric development [e.g., Mair and Marone, 1999; Beeler, this volume]. The effects are also important for rupture models that integrate friction laws and pore-fluid pressure changes driven by gouge layer volume changes [e.g., Segall and Rice, 1995]. We have documented a measure of gouge layer dilatancy, $\alpha=\Delta h / \Delta \log V$, where $h$ is gouge layer thickness and $V$ is sliding velocity [e.g., Marone and Kilgore, 1993]. To calculate $\alpha$, we first detrend the measured layer thickness to account for monotonic thinning owing to simple shear.

For both smectite and illite shale, $\alpha$ is generally positive (indicating dilation with increased sliding velocity), and we observe little variability in $\alpha$ with velocity or shear strain [Saffer and Marone, 2003]. For smectite, $\alpha$ ranges from -0.2 to $2.5 \mu \mathrm{m}$; values for illite shale range from 0.65 to $3.2 \mu \mathrm{m}$. Smectite exhibits some variability in $\alpha$ with normal stress, with higher values at low normal stress, whereas for illite shale values of $\alpha$ are scattered but exhibit no systematic variation over the range of normal stresses investigated.

Existing studies have not investigated the role of saturation or controlled pore pressure within gouge layers. The frictional strength of pure smectite has been shown to decrease with saturation, by as much as a factor of 2 [Morrow et al., 1992, 2000]. In contrast, Morrow et al. [1992] showed that the coefficient of sliding friction for illite shale is not appreciably affected by saturation, consistent with the fact that illite is not a hydrous clay mineral. For both smectite and illite the effects of saturation on constitutive parameters, including frictional velocity dependence, are not well characterized, although Morrow et al. [1992, 2000] showed that illite shale exhibits velocity-strengthening behavior when saturated, albeit under an extremely limited set of experimental conditions. These observations suggest that saturation state does not affect illite frictional properties significantly, although additional experiments are clearly needed. We also note that $\alpha$ is positive for illite shale, indicating dilatancy with increased sliding velocity. This volume increase should result in further velocity strengthening in saturated gouges, by decreasing pore pressure during slip (dilation), rather than potentially causing weakening by transient porepressure increase. 
Figure 12.11 shows the friction-rate parameter $(a-b)$ for smectite and illite shale [from Saffer and Marone, 2003] as a function of depth, assuming an effective stress gradient of $10 \mathrm{MPa} / \mathrm{km}$. The dependence of $(a-b)$ on shear strain for quartz [from Mair and Marone, 1999] is shown for comparison. For the quartz gouge, shear strain is converted to depth $z$, using a linear relationship between depth and shear strain, under the assumption that because fault displacement along subduction megathrusts increases with depth and distance from the trench, shear strain should increase systematically with depth. In addition, shearing-induced localization and gouge consolidation in laboratory experiments are reasonable proxies for consolidated behavior caused by greater pressures and temperatures at depth. Although the transition depth from velocity strengthening to velocity weakening in figure 12.11 is arbitrary, the form of the curve mimics the thermally driven transition of $(a-b)$ documented in several studies [e.g., Blanpied et al., 1995, 1998].

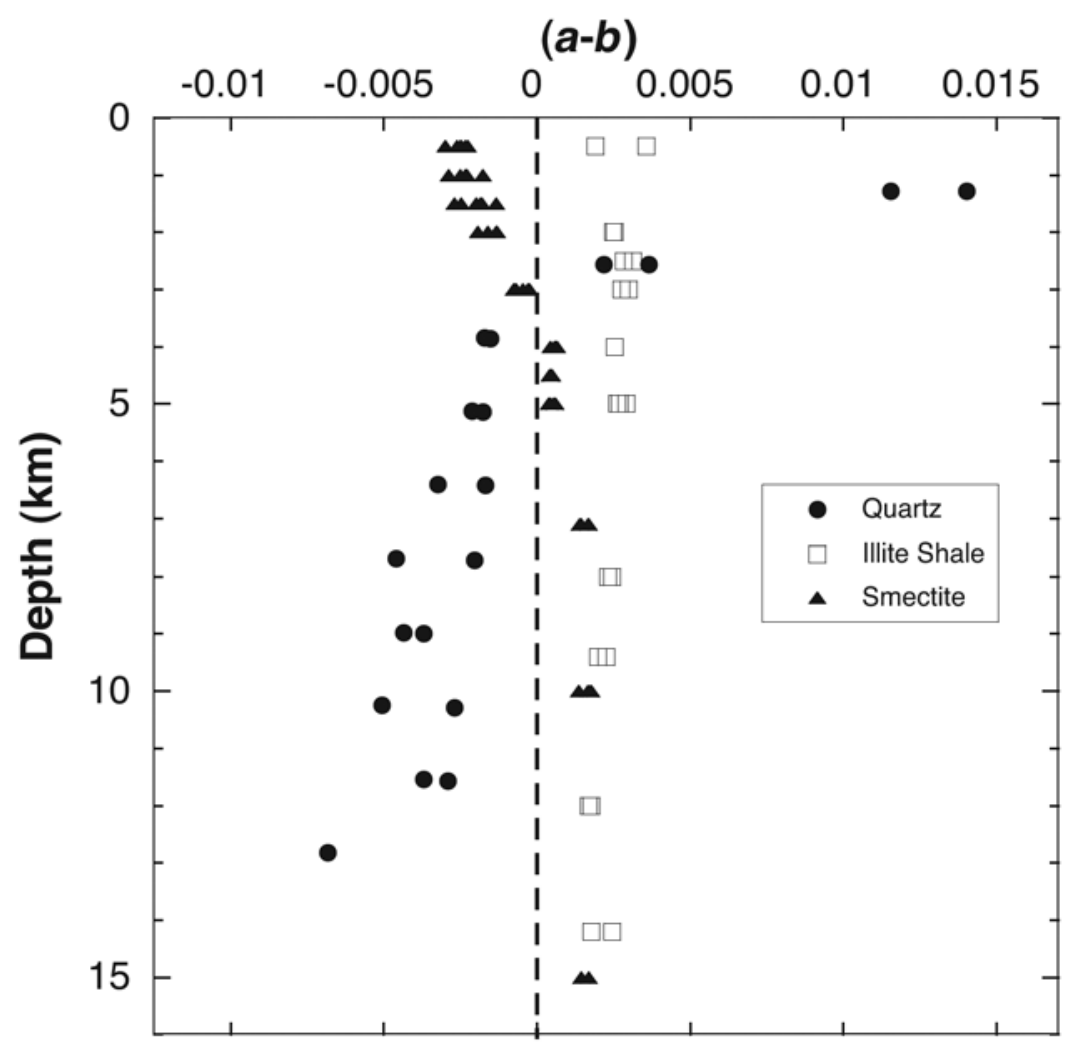

Figure 12.11 Variation of the friction rate parameter with depth for quartz and clays. Shear strain is converted to depth $z$, assuming that because fault displacement along subduction megathrusts increases with depth and distance from the trench, shear strain should increase systematically with depth. Data from Saffer and Marone [2003] and Mair and Marone [1999]. 


\section{Conclusions}

Contrary to the hypothesized velocity weakening of illite invoked to explain the onset of seismogenic slip at subduction zones, illite shale exhibits only velocity-strengthening behavior over the range of experimental conditions that have been explored to date. Although we cannot rule out the possibility of velocity-weakening behavior at higher temperatures or larger shear strains, these results over a wide range of experimental conditions (normal stress, shear strain, and sliding velocity) are inconsistent with the hypothesis that mineral transformation of stably sliding smectite to illite acts as a sole control on the updip limit of the seismogenic zone.

The results of laboratory experiments on relevant materials to date indicate that the transformation of smectite is unlikely to control the shallow transition from stable sliding to unstable slip along subduction megathrusts. Although it is clear that additional work is needed to rigorously evaluate the clay mineral hypothesis under a wider range of experimental conditions, such as elevated temperature, saturation and controlled pore pressure, and large shear strains, additional evidence from drilling also suggests that smectite transformation is not a universal explanation for the updip limit of seismicity. First, many convergent margins are characterized by little or no smectite in incoming sediments; yet these subduction zones still exhibit a clear updip limit of earthquakes [e.g., Moore and Saffer, 2001]. Second, in some cases, such as the southwest Nankai margin, smectite within the incoming sediments is transformed to illite outboard of the trench [e.g., Steuerer and Underwood, 2003]; yet the updip extent of microseismicity occurs tens of kilometers landward.

Taken together, the existing evidence suggests that other processes act to control the location of the upper aseismic-seismic transition [e.g., Moore and Saffer, 2001; Saffer and Marone, 2003]. These processes include the following: increased shear strain with depth along the plate interface and associated increased consolidation state of gouge and sediments (resulting in a transition from distributed to localized shear) [e.g., Marone and Scholz, 1988; Davis et. al, 1994], quartz cementation and pressure solution that may be associated with clay transformation [Moore and Saffer, 2001], and increasing effective stress, which may be mediated by pore pressure variations [Moore and Saffer, 2001; Scholz, 1998].

\section{Acknowledgments}

We thank the organizers of the SEIZE workshop and theoretical institute and the Margins community for feedback and insight on the many factors that influence the seismogenic zone. We are grateful for a thorough and insightful review by Nick Beeler and for the editorial work of Tim Dixon. This work is a result of partial support under grants OCE-0196462 and EAR-0196570, which is gratefully acknowledged. The authors also thank Jennifer Anthony for help with laboratory work. 


\section{References}

Archuleta, R. J. (1984), A faulting model for the 1979 Imperial Valley earthquake, J. Geophys. Res., 89, 4559-4585.

Beeler, N. M. (2007), Laboratory-observed faulting in intrinsically and apparently weak materials: Strength, seismic coupling, dilatancy, and pore fluid pressure, this volume.

Beeler, N. M., T. E. Tullis, and J. D.Weeks (1996), Frictional behavior of large displacement experimental faults, J. Geophys. Res., 101, 8697-8715.

Blanpied, M. L., D. A. Lockner, and J. D. Byerlee (1995), Frictional slip of granite at hydrothermal conditions, J. Geophys. Res., 100, 13,045-13064.

Blanpied, M. L., C. Marone, D. A. Lockner, J. D. Byerlee, and D. P. King (1998), Quantitative measure of the variation in fault rheology due to fluid-rock interactions, J. Geophys. Res., 103, 9691-9712.

Bos, B., and C. J. Spiers (2000), Effect of phyllosilicates-on fluid-assisted healing behaviour of gouge-bearing faults, Earth Planet. Sci. Lett., 184, 199-210.

Bos, B., and C. J. Spiers, (2002), Frictional-viscous flow of phyllosilicate-bearing fault rock: Microphysical model and implications for crustal strength profiles, J. Geophys. Res., 107I(B2), 2028, 10.1029/2001JB000301.

Bowden, F. P., and D. Tabor. (1950), The Friction and Lubrication of Solids. Part I. Clarendon, Oxford, U.K.

Brace, W. F., and D. L. Kohlstedt (1980), Limits on lithospheric stress imposed by laboratory experiments, J. Geophys. Res., 85, 6248-6252.

Bridgeman, P. W. (1936), Shearing phenomena at high pressure of possible importance to geology, J. Geol., 44, 653-669.

Davis, D. M., et al. (1994), Porosity loss in the evolution of accretionary wedges; some mechanical and seismic implications, in Proceedings of the Workshop LXIII, USGS Red-Book Conference on the Mechanical Involvement of Fluids in Faulting, U.S. Geol. Surv. Open File Rep., 94-0228, 460-465.

Deng, X., and M. B. Underwood (2001), Abundance of smectite and the location of a plateboundary fault, Barbados accretionary prism, Geol. Soc. Am. Bull., 113, 495-507.

Dieterich, J. H. (1979), Modeling of rock friction: 1. Experimental results and constitutive equations, J. Geophys. Res., 84, 2161-2168.

Dieterich, J. H. (1981), Constitutive properties of faults with simulated gouge, in Mechanical Behavior of Crustal Rocks, Geophys. Monogr. Ser., vol. 24, edited by N. L. Carter et al., pp. 103-120, AGU, Washington, D. C.

Dieterich, J. H. (1986), A model for the nucleation of earthquake slip, in Earthquake Source Mechanics, Geophys. Monogr. Ser., vol. 37, edited by S. Das, J. Boatwright, and C. H. Scholz, pp. 37-47, AGU, Washington, D. C.

Doser, D. I., and H. Kanamori (1986), Depth of seismicity in the Imperial Valley region 1977-1983 and its relationship to heat flow, crustal structure, and the October 15, 1979 earthquake, J. Geophys. Res., 91, 675-688.

Dragert, H., K. Wang, and T. S. James (2001), A silent slip event on the deeper Cascadia subduction interface, Geophys. Res. Lett., 292, 1526-1528.

Fuis, G. S., W. D. Mooney, J. H. Healy, G. A. McMechan, and W. J. Lutter (1982), Crustal structure of the Imperial Valley region, the Imperial Valley, California, earthquake of October 15, 1979, U.S. Geol. Surv. Prof. Pap., 1254, 25-49.

Hyndman, R. D., M. Yamano, and D. A. Oleskevich (1997), The seismogenic zone of subduction thrust faults, Island Arc, 6, 244-260.

Ida, Y. (1972), Cohesive force across the tip of a longitudinal-shear crack and Griffith's specific surface energy, J. Geophys. Res., 77, 3796-3805.

Logan, J. M., and K. A. Rauenzahn (1987), Frictional dependence of gouge mixtures of quartz and montmorillonite on velocity, composition, and fabric, Tectonophysics, 144 , 87-108.

Lupini, J. F., A. E. Skinner, and P. R. Vaughan (1981), The drained residual strength of cohesive soils, Geotechnique, 31, 181-213. 
Mair, K. and C. Marone (1999), Friction of simulated fault gouge for a wide range of velocities and normal stresses, J. Geophys. Res. (B), 104, 28899-28914.

Marone, C. (1998), Laboratory-derived friction constitutive laws and their application to seismic faulting, Annu. Rev. Earth Planet. Sci., 26, 643-696.

Marone, C., and B. Kilgore (1993), Scaling of the critical slip distance for seismic faulting with shear strain in fault zones, Nature, 362, 618-621.

Marone, C. , and C. H. Scholz (1988), The depth of seismic faulting and the upper transition from stable to unstable slip regimes. Geophys. Res. Lett., 15, 621-624.

Marone, C., C. B. Raleigh, and C. H. Scholz (1990), Frictional behavior and constitutive modeling of simulated fault gouge, J. Geophys. Res., 95, 7007-7025.

Marone, C., C. H. Scholz, and R. Bilham (1991), On the mechanics of earthquake afterslip, J. Geophys. Res., 96, 8441-8452.

Marone, C., B. E. Hobbs, and A. Ord (1992), Coulomb constitutive laws for friction: Contrasts in frictional behavior for distributed and localized shear, Pure Appl. Geophys., 139, 195-214.

McGuire, J. J., and P. Segall (2003), Imaging of aseismic fault slip transients recorded by dense geodetic networks, Geophys. J. Int., 155, 778-788.

Miller, M. M., T. Melbourne, D. J. Johnson, and W. Q. Sumner (2002), Periodic slow earthquakes from the Cascadia subduction zone, Science, 295, 2423-2424.

Moore, G. F., et al. (2001), New insights into deformation and fluid flow processes in the Nankai Trough accretionary prism: Results of Ocean Drilling Program Leg 190, Geochem. Geophys. Geosyst., 2(10), doi:10.1029/2001GC000166.

Moore, J. C., and D. M. Saffer (2001), Updip limit of the seismogenic zone beneath the accretionary prism of southwest Japan: An effect of diagenetic to low-grade metamorphic processes and increasing effective stress, Geology, 29(2), 183-186.

Morrow, C. A., L. Q. Shi, and J. D. Byerlee (1982), Strain hardening and strength of clay-rich fault gouges, J. Geophys. Res., 87, 6771-6780.

Morrow, C. A., B. Radney, and J. D. Byerlee (1992), Frictional strength and the effective pressure law of montmorillonite and illite clays, in: B. Evans, Ed., Fault Mechanics and Transport Properties of Rocks, edited by B. Evans, pp. 69-88, CRC Press, Boca Raton, Fla.

Morrow, C. A., D. E. Moore, and D. A. Lockner (2000), The effect of mineral bond strength and absorbed water on fault gouge frictional strength, Geophys. Res. Lett., 27,815-818.

Oleskevich, D. A., R. D. Hyndman, and K. Wang (1999), The updip and downdip limits to great subduction earthquakes: Thermal and structural models of Cascadia, South Alaska, SW Japan, and Chile, J. Geophys. Res., 104, 14,965-14,991.

Palmer, A. C. and J. R. Rice, The growth of slip surfaces in the progressive failure of over- consolidated clay, Proc. Roy. Soc. Lond. A332, 527-548, 1972.

Peacock, S. M., and R. D. Hyndman (1999), Hydrous minerals in the mantle wedge and the maximum depth of subduction thrust earthquakes. Geophys. Res. Lett., 26, 2517-2520.

Perfettini, H., J. Schmittbuhl, J. R. Rice, and M. Cocco (2001), Frictional response induced by time-dependent fluctuations of the normal load, J. Geophys. Res., 106, 13,455-13,472.

Pytte, A. M., and R. C. Reynolds (1988), The thermal transformation of smectite to illite, in Thermal Histories of Sedimentary Basins, edited by T. H. McCulloh and N. D. Naeser, pp. 133-140, Springer, New York.

Quin, H. (1990), Dynamic stress drop and rupture dynamics of the October 15, 1979 Imperial Valley earthquake, Tectonophysics, 175, 93-117.

Rabinowicz, E. (1951), The nature of static and kinetic coefficients of friction, J. Appl. Phys., 22, 1373-1379.

Rabinowicz, E. (1956), Stick and slip, Sci. Am., 194, 109-118.

Reinen, L. A., J. D. Weeks, and T. E. Tullis (1994), The frictional behavior of lizardite and antigorite serpentinites: Experiments, constitutive models and implications for natural faults, Pure Appl. Geophys., 143, 317-358.

Rice, J. R. (1983), Constitutive relations for fault slip and earthquake instabilities, Pure Appl. Geophys., 121, 443-475. 
Rice, J. R. (1993), Spatio-temporal complexity of slip on a fault, J. Geophys. Res., 98, 9885-9907.

Rice, J. R., and A. L. Ruina (1983), Stability of steady frictional slipping, J. Appl. Mech., 50, 343-349.

Richardson, E., and T. H. Jordan (2002), Seismicity in deep gold mines of South Africa: Implications for tectonic earthquakes, Bull. Seismol. Soc. Am., 92 , 1766-1782.

Roy, M., and C. Marone (1996), Earthquake nucleation on models faults with rate and state dependent friction: The effects of inertia, J. Geophys. Res., 101, 13,919-13,932.

Ruina, A. (1983), Slip instability and state variable friction laws, J. Geophys. Res., 88, 10, $359-10,370$.

Saffer, D. M., and C. Marone (2003), Comparison of smectite- and illite-rich gouge frictional properties: Implications for the updip limit of the seismogenic zone along subduction megathrusts, Earth Planet. Sci. Lett., 215, 219-235.

Saffer, D. M., K. M. Frye, C. Marone, and K. Mair (2001), Laboratory results indicating complex and potentially unstable frictional behavior of smectite clay, Geophys. Res. Lett., 28, 2297-2300.

Satake, K. (1994), Mechanism of the 1992 Nicaragua tsunami earthquake, Geophys. Res. Lett., 21, 2519-2522.

Scholz, C. H. (1988), The critical slip distance for seismic faulting, Nature, 336, 761-763.

Scholz, C. H. (2002), The Mechanics of Earthquakes and Faulting, 2nd ed., Cambridge Univ. Press, New York.

Segall, P., and J. R. Rice (1995), Dilatancy, compaction, and slip instability of a fluid infiltrated fault, J. Geophys. Res., 100, 22,155-22,173.

Sibson, R. H. (1982), Fault zone models, heat flow, and the depth distribution of earthquakes in the continental crust of the United States, Bull. Seismol. Soc. Am., 72, 151-163.

Sleep, N. H., and M. L. Blanpied (1992), Creep, compaction and the weak rheology of major faults, Nature, 359, 687-692.

Sleep, N. H., and M. L. Blanpied (1994), Ductile creep and compaction: A mechanism for transiently increasing fluid pressure in mostly sealed fault zones, Pure Appl. Geophys., 143, 9-40.

Steurer, J. F. and M. B. Underwood (2003), Clay Mineralogy of Mudstones from the Nankai Trough Reference Sites 1173 and 1177 and frontal accretionary prism site 11741, edited by H. Mikada, G. F. Moore, A. Taira, K. Becker, J. C. Moore, and A. Klaus, in Proc. Ocean Drill. Program Sci. Results 190/196, 22-33.

Tobin, H., P. Vannucchi, and M. Meschede (2001), Structure, inferred mechanical properties, and implications for fluid transport in the décollement zone, Costa Rica convergent margin: Geology, 29, 10, 907-910.

Tullis, T. E. (1988), Rock friction constitutive behavior from laboratory experiments and its implications for an earthquake prediction field monitoring program, Pure Appl. Geophys., $126,555-588$.

Underwood, M. B., et al. (1993), Sediment geochemistry, clay mineralogy, and diagenesis: A synthesis of data from leg 131, Nankai Trough, Proc. Ocean Drill. Program Sci. Results, $131,343-363$.

Vrolijk, P. (1990), On the mechanical role of smectite in subduction zones, Geology, 18(8), $703-707$.

Vrolijk, P., and B. A. Van der Pluijm (1999), Clay gouge, J. Struct. Geol., 21 1039-1048.

Wald, D. J., and T. H. Heaton (1994), Spatial and temporal distribution of slip for the 1992 Landers, California, earthquake, Bull. Seis. Soc. America, 84, 668-691.

Zhang, J., D. Davis, and T-F. Wong (1993), The brittle-ductile transition in porous sedimentary rocks: Geological implications for accretionary wedge aseismicity, J. Struct. Geol., 15, 819-830. 